NASA-TM-105,306

NASA Technical Memorandum 105306

ICOMP-91-20; CMOTT-91-09

NASA-TM-105306

19920009533

\title{
Multigrid Acceleration and Turbulence Models for Computations of 3D Turbulent Jets in Crossflow
}

A.O. Demuren

Old Dominion University

Norfolk, Virginia

and

Institute for Computational Mechanics in Propulsion Lewis Research Center

Cleveland, Ohio

November 1991

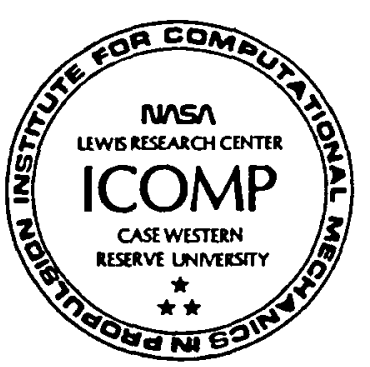




\title{
MULTIGRID ACCELERATION AND TURBULENCE MODELS FOR COMPUTATIONS OF 3D TURBULENT JETS IN CROSSFLOW
}

\author{
A.O. Demuren \\ Department of Mechanical Engineering and Mechanics \\ Old Dominion University \\ Norfolk, Virginia 23529 \\ and \\ Institute for Computational Mechanics in Propulsion \\ and Center for Modeling of Turbulence and Transition \\ Lewis Research Center \\ Cleveland, Ohio 44135
}

\begin{abstract}
A multigrid method is presented for the calculation of three-dimensional turbulent jets in crossflow. Turbulence closure is achieved with either the standard $k-\epsilon$ model or a Reynolds Stress Model (RSM). Multigrid acceleration enables convergence rates which are far superior to that for a single grid method to be obtained with both turbulence models. With the $k-\epsilon$ model the rate approaches that for laminar flow, but with RSM it is somewhat slower. The increased stiffness of the system of equations in the lattter may be reponsible. Computed results with both turbulence models are compared with experimental data for a pair of opposed jets in crossflow. Both models yield reasonable agreement with mean flow velocity, but RSM yields better predition of the Reynolds stresses.
\end{abstract}

NOMENCLATURE

$\begin{array}{ll}\mathrm{c}_{1}, \mathrm{c}_{\mathrm{s}} & \text { constants in Reynolds stress model } \\ \mathrm{c}_{\mu}, \mathrm{c}_{\epsilon 1}, \mathrm{c}_{\epsilon 2} & \text { constants in } \mathrm{k}-\epsilon \text { turbulence model } \\ \mathrm{D} & \text { jet diameter } \\ \mathrm{f} & \text { near-wall proximity function in Reynolds stress model } \\ \mathrm{G} & \text { rate of production of turbulent kinetic energy } \\ \mathrm{H} & \text { height of duct } \\ \mathrm{k} & \text { turbulent kinetic energy } \\ \mathrm{P} & \text { pressure } \\ \mathrm{R} & \text { jet to crossflow velocity ratio } \\ S_{\phi} & \text { source term for dependent variable } \Phi \\ U_{\infty} & \text { crossflow velocity } \\ \mathrm{U}_{\mathrm{i}} & \text { cartesian velocity components } \\ \overline{u_{1}^{2}}, \overline{u_{2}^{2}}, \overline{u_{3}^{2}}, & \text { Reynolds normal stresses in cartesian directions }\end{array}$




$\begin{array}{ll}\overline{u_{1} u_{2}}, \overline{u_{1} u_{3}}, \overline{u_{2} u_{3}} & \text { Reynolds shear stresses } \\ V_{\mathrm{j}} & \text { jet velocity } \\ y^{j} & \text { cartesian coordinates } \\ \alpha, \beta, \gamma & \text { constants in Reynolds stress model } \\ \delta_{\mathrm{ij}} & \text { Kronecker delta } \\ \epsilon & \text { rate of dissipation of turbulent kinetic energy } \\ \kappa & \text { von Karman constant } \\ \mu & \text { molecular viscosity } \\ \mu_{\mathrm{t}} & \text { turbulent eddy viscosity } \\ \rho & \text { density } \\ \sigma_{\phi} & \text { turbulent Prandtl/Schmidt number for } \Phi \\ \Phi & \text { General representation of dependent variable }\end{array}$

Superscripts

lateral direction

2

vertical direction

3

longitudinal direction

\section{INTRODUCTION}

Three-dimensional turbulent jets in crossflow have important engineering applications in both confined and unconfined environments. Examples of jets issuing into confined crossflow include internal cooling of turbine blades, dilution air jets in combustion chambers, jets from V/STOL aircraft in transition flight, etc. The examples of turbulent jets issuing into unconfined (semiinfinite) crossflow are even more numerous. These include discharges from cooling towers or chimney stacks into the atmosphere or sewerage and waste heat into water bodies, film-cooling of turbine blades, etc.

The interaction of the jets with the crossflow has been investigated in numerous experimental studies [1-6]. Crabb et al [2] present a comprehensive review of pre 1980 studies, most of which only deal with mean flow properties. Measurements of turbulent properties can be found in [26]. Numerous computational studies of the generic problem of turbulent jets in crossflow are also reported in the literature [7-10]. Demuren [11] presents an extensive review of the various modeling approaches. Due to computational expense, none of the earlier studies use sufficiently fine grids. In a recent paper, Claus and Vanka [12] present a systematic study of the effect of grid resolution on the mean flow and turbulence fields. These show that for computational grids up to 
$96 \times 96 \times 256$ grid-independent solutions could not be obtained. They use a multigrid method so that the natural progression for grid refinement is to double the number of grid points in each direction, which is more stringent than the grid-dependency tests in most other studies. There have also been frequent questions as to the role of the turbulence model in predicting correctly this rather complicated flow. Most computations employ the $k-\epsilon$ turbulence model which assumes gradient diffusion relations for the Reynolds stress and an isotropic eddy-viscosity distribution. Andreopoulos and Rodi [4] show by analyzing their measurements of Reynolds stresses and the velocity gradients that this approach is only partly supported by experimental evidence. In some regions, the turbulent stress field is out of balance with the mean velocity strain field so that the Boussinesq eddy-viscosity hypothesis would require negative eddy viscosities which the $k-\epsilon$ turbulence does not allow for. Further, locations of zero stresses do not coincide with those with zero velocity gradients.

The present study attempts to address both the problems of grid resolution and the turbulence model. Computations are performed with a multi-grid procedure which enables convergence on very fine grids within a relatively small number of iterations. The Reynolds stresses are computed with a second-moment turbulence closure model as well as the standard $\mathrm{k}-\epsilon$ model.

\section{MATHEMATICAL MODEL}

\section{Mean Flow Equations}

In the present work, the time-averaged, three dimensional, steady-state equations governing the turbulent flow form the basis for the numerical method. The equations may be expressed, in conservative form and cartesian tensor notation as:

Continuity

$$
\frac{\partial}{\partial y^{l}}\left(\rho U_{l}\right)=0
$$

Momentum

$$
\frac{\partial}{\partial y^{l}}\left(\rho U_{l} U_{i}\right)=-\frac{\partial}{\partial y^{i}} P+\frac{\partial}{\partial y^{l}}\left[-\rho \overline{u_{i} u_{l}}+\mu\left(\frac{\partial U_{i}}{\partial y^{l}}+\frac{\partial U_{l}}{\partial y^{i}}\right)\right]
$$

with $\mathrm{i}=1,2,3$ and $l=1,2,3$ representing properties in the lateral, vertical and longitudinal directions, respectively. $y^{i}\left(=y^{1}, y^{2}, y^{3}\right)$ represent the Cartesian coordinates; $U_{i}$ the Cartesian velocity components; $\mathrm{P}$ the pressure; $\rho$ the density and $\mu$ the molecular viscosity. The equations are expanded with Einstein's summation rule for repeated indices. $-\rho \overline{u_{i} u_{l}}$ represents the Reynolds stress tensor which is symmetric with 6 independent components to be determined before the mean flow equations can be closed. This is the task of the turbulence model. 


\section{Turbulence Models}

In the present work, the Reynolds stresses are determined from either the $k-\epsilon$ model described in detail by Launder and Spalding [13] or the quasi-isotropic version of the Reynolds stress models of Launder, Reece and Rodi [14], hereafter denoted LRR.

In the $k-\epsilon$ model, the Reynolds stresses are calculated with the Boussinesq eddy viscosity hypothesis as:

$$
-\rho \overline{\mathrm{u}_{\mathrm{i}} \mathrm{u}_{l}}=\mu_{\mathrm{t}}\left(\frac{\partial \mathrm{U}_{\mathrm{i}}}{\partial \mathrm{y}^{\mathrm{l}}}+\frac{\partial \mathrm{U}_{l}}{\partial \mathrm{y}^{\mathrm{i}}}\right)-\frac{2}{3} \rho \mathrm{k} \delta_{\mathrm{i} l}
$$

where $\delta_{\mathrm{il}}$ is the Kronecker delta which is equal to unity when $\mathrm{i}=l$ and zero when $\mathrm{i} \neq l$. The form of equation (3) ensures that the trace of tensor $\overline{\mathrm{u}_{\mathrm{i}} \mathrm{u}_{l}}$ is equal to twice the turbulent kinetic energy.

$\mu_{\mathrm{t}}$ is the eddy viscosity given by:

$$
\mu_{\mathrm{t}}=\mathrm{c}_{\mu} \rho \frac{\mathrm{k}^{2}}{\epsilon}
$$

Thus, in other to compute $\mu_{\mathrm{t}}$, the distributions of the turbulent kinetic energy $\mathrm{k}$ and its rate of dissipation $\epsilon$ over the computational domain are required. These are obtained by solving the transport equations:

$$
\begin{gathered}
\frac{\partial}{\partial y^{l}}\left(\rho U_{l} k\right)=\frac{\partial}{\partial y^{l}}\left(\frac{\mu_{t}}{\sigma_{k}} \frac{\partial k}{\partial y^{l}}\right)+G-\rho \epsilon \\
\frac{\partial}{\partial y^{l}}\left(\rho U_{l} \epsilon\right)=\frac{\partial}{\partial y^{l}}\left(\frac{\mu_{t}}{\sigma_{\epsilon}} \frac{\partial \epsilon}{\partial y^{l}}\right)+c_{\epsilon 1} G \frac{\epsilon}{k}-c_{\epsilon 2} \rho \frac{\epsilon^{2}}{k}
\end{gathered}
$$

where $\mathrm{G}$ is the rate of production of turbulent kinetic energy by the interaction of the Reynolds stresses with the mean flow, given by:

$$
\mathrm{G}=-\rho \overline{\mathrm{u}_{\mathrm{m}} \mathrm{u}_{l}} \frac{\partial \mathrm{U}_{l}}{\partial \mathrm{y}^{\mathrm{m}}}
$$

The empirical constants appearing in equations (4)-(7) are $c_{\mu}=0.09, c_{\epsilon 1}=1.44, c_{\epsilon 2}=1.92, \sigma_{\mathrm{k}}=1.0$ and $\sigma_{\epsilon}=1$.3. Equations (1)-(9) form a closed set which can be solved with a numerical method to yield the distributions of the three velocity components, the pressure, and the six components of the Reynolds stresses.

The Reynolds stress model does not assume the Boussinesq hypothesis. Rather, exact transport equations can be derived by combining the Navier-Stokes equations with their time-averaged versions, the so-called Reynolds equations. This does not, however, solve the turbulence closure problem since the equations contain terms of higher order which cannot be calculated exactly but must be modeled or approximated. The presumption then is that since these terms are thirdmoment statistics inaccuracies in approximating them will have much smaller effect on the mean 
flow than errors in modeling the second-moments. If the proposals of LRR [14] model 1 are adopted to approximate the pressure-strain, diffusion and dissipation terms, the resulting system of equations can be written in cartesian tensor notation as:

$$
\begin{gathered}
\frac{\partial}{\partial \mathrm{y}^{l}}\left(\rho \mathrm{U}_{l} \overline{\mathrm{u}_{\mathrm{i}} \mathrm{u}_{\mathrm{j}}}\right)=\frac{\partial}{\partial \mathrm{y}^{l}}\left(c_{\mathrm{s}} \rho \frac{\mathrm{k}}{\epsilon} \overline{\epsilon \mathrm{u}_{\mathrm{m}}} \frac{\partial \overline{\mathrm{i}_{\mathrm{i}} \mathrm{u}_{\mathrm{j}}}}{\partial \mathrm{y}^{\mathrm{m}}}\right) \\
-\rho\left\{(1-\alpha)\left[\overline{\mathrm{u}_{\mathrm{i}} \bar{u}_{l}} \frac{\partial \mathrm{U}_{l}}{\partial \mathrm{y}^{\mathrm{j}}}+\overline{\mathrm{u}_{\mathrm{j}} \overline{\mathrm{u}}_{l}} \frac{\partial \mathrm{U}_{l}}{\partial \mathrm{y}^{\mathrm{i}}}\right]\right. \\
-\beta\left[\overline{\mathrm{u}_{\mathrm{i}} \mathrm{u}_{l}} \frac{\partial \mathrm{U}_{\mathrm{i}}}{\partial \mathrm{y}^{l}}+\overline{\mathrm{u}_{\mathrm{j}} \mathrm{u}_{l}} \frac{\partial \mathrm{U}_{l}}{\partial \mathrm{y}^{\mathrm{i}}}\right]+\frac{2}{3} \delta_{\mathrm{ij}}(\alpha+\beta) \overline{\mathrm{u}_{l} \mathrm{u}_{\mathrm{m}}} \frac{\partial \mathrm{U}_{l}}{\partial \mathrm{y}^{\mathrm{m}}} \\
\left.+\gamma \mathrm{k}\left(\frac{\partial \mathrm{U}_{\mathrm{j}}}{\partial \mathrm{y}^{\mathrm{i}}}+\frac{\partial \mathrm{U}_{\mathrm{i}}}{\partial \mathrm{y}^{\mathrm{j}}}\right)+\frac{\mathrm{c}_{1} \epsilon}{\mathrm{k}}\left(\overline{\mathrm{u}_{\mathrm{i}} \mathrm{u}_{\mathrm{j}}}-\frac{2}{3} \delta_{\mathrm{ij}^{\mathrm{j}} \mathrm{k}}\right)+\frac{2}{3} \delta_{\mathrm{ij}} \epsilon\right\}
\end{gathered}
$$

$\alpha, \beta, \gamma, c_{1}$ and $c_{s}$ are empirical coefficients given by: $\alpha=0.7636-0.06 f ; \beta=0.1091+0.06 f$; $\gamma=0.182 ; c_{1}=1.5-0.50 \mathrm{f} ;$ and $c_{s}=0.22$. $\mathrm{f}$ is a wall-proximity function which takes a value of unity near walls and zero in a homogeneous flow with no walls. Thus an attempt is made to interpolate the coefficients between values found empirically in two asymptotic flows. The method for calculating $f$ is described in detail by Demuren and Rodi [15]. Equations (1), (2), (6) and (8) now form a closed set which should be solved simultaneously by the numerical method to determine the mean-flow and turbulence fields.

If the terms involving gradients of the Reynolds stresses on the r.h.s. of Eq. (2) are treated explicitly the system of equations will be very stiff and it will be extremely difficult to obtain a converged solution with an iterative scheme. The stiffness can be reduced considerably by splitting the Reynolds stress $\overline{u_{i} u_{l}}$ into two parts:

$$
\overline{u_{i} u_{l}}=\overline{u_{i} u_{l}^{\prime}}-\frac{\mu_{t}}{\rho}\left(\frac{\partial U_{i}}{\partial y^{l}}+\frac{\partial U_{l}}{\partial y^{i}}\right)
$$

The first part is treated explicitly. The second part is added to the molecular diffusion term and treated implicitly. The modified momentum equation has the form:

$$
\frac{\partial}{\partial y^{l}}\left(\rho U_{l} U_{i}\right)=-\frac{\partial}{\partial y^{i}} P+\frac{\partial}{\partial y^{l}}\left[-\rho \overline{u_{i} u_{l}^{\prime}}+\left(\mu+\mu_{t}\right)\left(\frac{\partial U_{i}}{\partial y^{l}}+\frac{\partial U_{l}}{\partial y^{i}}\right)\right]
$$




\section{Discretization Method}

A finite-volume numerical method is used in the present study to convert the transport equations from partial-differential form to algebraic ones which are then solved iteratively. The computation domain is divided into a finite grid of control volumes (CV) with the unknown value of the dependent variables assumed stored at the center of each $\mathrm{CV}$, i.e. a non-staggered grid arrangement is used. The conservation equations are satisfied over each CV by using Green's theorem to convert volume integrals of the equations to surface integrals which represent the fluxes in and out of its six surfaces. Now these fluxes must be related to nodal values which are located at the center of the CV's. Figure 1 shows a typical CV with its six neighbouring nodes. The diffusion fluxes are approximated with central differences. The convection terms require special treatment. It is well known that central difference approximation of convection terms in highly convective flows leads to odd-even decoupling, non-physical oscillatory solution, and perhaps instability. To overcome the odd-even decoupling problem it has been popular in incompressible flow codes [16] to stagger the nodes for the velocity components by half a cell in each direction relative to the other nodes, whereas in compressible flow codes [17] a fourth-order artificial dissipation term is added to the density equation. Examination of the continuity equation shows that it contains only convection terms, hence the odd-even decoupling problem results from mainly using central differences in this equation. In compressible flow codes the dependent variable resulting from this equation is the density, hence the form of the artificial dissipation term. Most incompressible flow codes do not solve equation (1) directly but solve a form of poisson equation for pressure derived by combining equations (1) and (2). Hence, staggering of the grid nodes indirectly introduces upwind differences for pressure, and since the stabilizing properties of upwind differencing is due indirectly to the introduction of artificial diffusion/dissipation, both approaches are successful for similar reasons. Rhie [18] has analyzed the stability of pressure based solvers on a non-staggered grid using a fourthorder artificial dissipation pressure term. This practice is followed in the present work. The difference in practice so far appears to be largely historical. Incompressible flow codes were originally designed for internal flows and finite differences were used on rectangular grids where staggering was very easy to implement. With the conversion to finite volume formulation and the need for curvilinear grids staggering became messy and the approach of Rhie and Chow [19] has now become common practice. This is also sometimes called "momentum interpolation" [20], a terminology which is unfortunate since it clouds the real process. Compressible flow codes on the other hand, required body-fitted coordinates so that grid staggering was never an attractive option. 
Some form of upwinding or artificial dissipation is also required for the remaining equations. For these the hybrid (central/upwind) difference scheme [16] is adopted. With these approximations the unknown nodal value is linked to those of its six nearest neighbours by an algebraic equation of the form:

$$
A_{p} \phi_{p}=\sum_{n b} A_{n b} \phi_{n b}+S_{\phi}
$$

where $\mathrm{nb}=\mathrm{E}, \mathrm{W}, \mathrm{N}, \mathrm{S}, \mathrm{U}, \mathrm{D}$ and $\phi$ represents any of the dependent variables.

Boundary conditions are used to specify the dependent variable values along the six boundaries. Four types of boundary conditions are encountered in the present study; namely inlet, outlet, symmetry planes and walls. Inlet conditions are specified from experimental data, if known. The outlet is an outflow boundary along which the first derivative of all variables is set to zero. Along symmetry planes the normal gradient of all variables is set to zero, and the normal velocity is also zero. The walls are treated specially because integration of the equations is not carried all the way down to the walls, but the wall-function method $[13,15]$ is used to prescribe values of dependent variables along the nearest grid nodes.

The equation set for all internal nodes in the computational domain must be solved simultaneously. An ADI scheme is utilized for this purpose. The equations are solved in a sequential manner, one variable at a time, based on the SIMPLEC algorithm described by van Doormaal and Raithby [21]. In the present multigrid context, this algorithm serves primarily as a relaxation scheme with the important requirement being its smoothing properties. Shaw and Sivaloganathan [22] have shown that the SIMPLE algorithm on which it is based has good smoothing properties. One cycle of the relaxation scheme has the following steps:

1. Solve the $U_{1}$ momentum equation using available pressure field.

2. Then the $U_{2}$ momentum equation.

3. Then the $\mathrm{U}_{3}$ momentum equation.

4. Compute mass fluxes through the faces of $\mathrm{CV}$ by linear interpolation of velocity field plus fourth order artificial dissipation terms in pressure. (As explained this is equivalent to upwind weighting of pressure gradients).

5. Compute mass source errors.

6. Solve an equation for the correction to the pressure field necessary to eliminate the mass source errors, and then correct the pressure and velocity fields 


\section{Multigrid Procedure}

In the present work the FAS-FMG (full approximation storage - full multigrid) algorithm originally developed by Brandt [23] is employed to solve the mean-flow equations. The present implementation derives from previous work by Demuren [24]. The main differences relate to the changes to the relaxation scheme due to non-staggered grids and the sequential solution steps discussed in the preceding section. Numerical experiments showed no advantage in using the coupled approach proposed by Vanka [25] implemented in [24], and it can be shown mathematically that it is less stable in a single-grid procedure. Further, the sequential approach is more easily vectorizable.

The multigrid process starts on the coarsest grid with relaxation cycles repeated until convergence. The next finer grid is then generated by halving the sizes of control volume sides in each direction. The coarse grid results are then prolongated onto the fine grid to provide initial conditions. The multigrid process then cycles between the two grids until convergence is obtained on the finer grid. The next finer grid is then generated and initialized as before. The MG process now cycles between the three grids until convergence. The present implementation uses V-cycles with 1 relaxation sweep on the finest grid before residuals are restricted to a coarser grid, and 1 relaxation is also performed on each intermediate grid. 5 relaxation sweeps are performed on the coarsest grid. This is not the most efficient cycling scheme, but it was found to be a good compromise between robustness and efficiency in a wide range of test cases.

Restriction and prolongation operators are required to transfer the fine grid approximations and residuals onto coarse grids and the coarse grid corrections onto the fine grid, respectively. Residuals are restricted by simply summing the residuals of the eight fine grid CV's that make up each coarse grid CV. Otherwise, trilinear interpolation is used for restricting the primitive variables or prolongating the corrections.

The equations for turbulent quantities $\mathrm{k}, \epsilon$ and $\overline{u_{i} u_{j}}$ are only solved on current finest grid level during the MG process. Values required for diffusion fluxes or source terms on coarser grids are restricted from these. In future work, the MG process will be extended to these variables as well. The scheme must be modified however to ensure that $k, \epsilon$ and the normal stress components $\overline{u_{1}^{2}}, \overline{u_{2}^{2}}$ and $\overline{u_{3}^{2}}$ can never become negative at any stage. 


\section{RESULTS AND DISCUSSION}

\section{Computational Details}

The test case for the present work is selected from experimental studies of pairs of opposed jets discharging normally into a cross-stream reported by Atkinson et al [3]. Figure 2 shows a schematic diagram. Two jets of equal diameter $D$ issue at the same velocity from opposite pipes into a cross stream. The channel height is equal to $4 \mathrm{D}$ and the width is $12 \mathrm{D}$. The jet to crossflow velocity ratio $\mathrm{R}$ is 1.8 and the Reynolds number based on the crossstream velocity and channel height is $1.1 \times 10^{5}$. An indication of the grid distribution is given in Fig. 3 which shows the velocity vectors in the center plane computed on the finest grid of a 3-level MG scheme. The coarsest grid has $(12 \times 10 \times 22)$ points in the $\left(y^{1}, y^{2}, y^{3}\right)$ directions. There are two planes of symmetry so computations are only performed for a quarter section of the flow domain which extends from 4D upstream of the jet hole to $14 \mathrm{D}$ downstream. The vector plots show that the jets from opposite sides impinge at the mid-plane about $1 \mathrm{D}$ downstream.

\section{Convergence Rates}

In order to evaluate the multigrid performance laminar flow calculations were made for the configuration of Fig. 2, but with the outlet plane at 4D downstream of the jet hole, and a crossstream Reynolds number of 100 . Three calculations were made: single grid, 2-level MG and 3-level MG. The finest grid in each case has $(42 \times 34 \times 82)$ points in the $\left(y^{1}, y^{2}, y^{3}\right)$ directions. The residuals of the momentum and continuity equations are plotted against the number of iterations in Fig. 4. MG acceleration is clearly demonstrated, with reduction of 3-4 orders of magnitude in about 50 cycles, corresponding to a spectral radius (error reduction rate per cycle) of about 0.85 . Figure 5 shows the history of the $U_{2}$ and $U_{3}$ velocity components at a typical point (1D, 1D, 1D) in the domain. The 3-level MG results reach the asymptotic values in about 5 cycles, the 2-level MG in about 30 cycles and the single grid results are still long ways away. Of course, the FMG scheme ensures that the initial values on fine grids are good guesses of the final answer since they are interpolated from converged coarse grid results. Each MG cycle of the 3-grid-level calculations took 2 seconds of CPU time on the Cray YMP, 25\% of which was overhead for prolongations, restrictions and smoothings on coarser grids.

The residual histories for laminar, $\mathrm{k}-\epsilon$ model and RSM calculations on the 3-level MG are compared in Fig. 6. There is again rapid convergence in the first 50 cycles, thereafter the convergence rate deteriorated with the complexity of the system of equations. The turbulent flow computations were made at $\operatorname{Re}=1.1 \times 10^{5}$, so they are not for exactly the same conditions as the laminar flow. 


\section{Grid Dependency}

It has not been possible to confirm grid independency within the limits of the available computer resources. Figure 8 compares vertical profiles of the streamwise velocity component in the center plane at $6 \mathrm{D}$ and $8 \mathrm{D}$ computed with a 3-level MG and a 4-level MG. The k- $\epsilon$ model is used in both computations. Significant differences exist only near the mid-plane at $6 \mathrm{D}$, but at $8 \mathrm{D}$ the results are quite close. The differences are much smaller than those reported by Claus and Vanka [12] in their study of a row of jets in crossflow. The differences are also small in comparison with deviations from experimental data. It should be noted that there is an eightfold difference in the number of grid points utilized. Calculations with RSM also show similar changes with grid refinement. In the light of these, all subsequent results to be presented are for calculations on the 3-level grid.

\section{Comparison with Experiment}

The present computations with the two turbulence models, on a 3-level grid, are compared with experimental results of Atkinson et al [3] in Figs. 9-11. Vertical profiles of the streamwise velocity component are compared in Fig. 9. The RSM predicts higher magnitudes near the midplane and lower magnitudes near the wall. In terms of agreement with experimental data, there is little to choose between them. The largest deviation from experimental data is at $12 \mathrm{D}$. Although the profiles are the same shape the experimental data indicate magnitudes which are $20 \%$ lower. In fact, the data show $10-15 \%$ reduction in the streamwise velocity between $8 \mathrm{D}$ and $12 \mathrm{D}$. This is unusual since it would be expected that the flow should tend towards more uniformity with distance downstream, and the normalized streamwise velocity should approach unity rather than deviate further from it. It is possible that there is a systematic error in the experimental data.

The Reynolds stresses are compared along the center plane, at axial locations $8 \mathrm{D}$ and $12 \mathrm{D}$ in Figs. 10 and 11, respectively. The $\mathrm{k}-\epsilon$ model consistently overpredicts the normal stresses. This indicates that the turbulent kinetic energy is overpredicted. The culprit is likely to be the production term $G$ (equation 7) which is known to lead to infinite turbulent kinetic energy near the impingement point in a stagnation flow, when used in conjunction with the eddy viscosity hypothesis. The RSM produces normal stresses which are in better agreement with the measurements, except $\overline{u_{2}^{2}}$ near the mid plane. At $8 \mathrm{D}$ both models predict excessive shear stress magnitudes in comparison with experimental data. At 12D, the RSM results agree better with the data. Another unusual feature of the data is that they indicate an increase in shear stress in going from $8 \mathrm{D}$ to $12 \mathrm{D}$, whereas one would expect a decrease, as the computations show. These experiments are, of course, quite difficult to perform. A slight difference in the flow properties of the opposing jets may lead to significant deviations from symmetry about the mid-plane and 
perhaps unsteadiness and other unexpected effects. On the other hand, the RSM predictions are far from perfect. The present version of RSM, based on the proposals of LRR [14], is one of the simplest and most widely tested. However, it is known to have shortcomings in complex flows with strong swirl and curvature. Recently, more complex RSM have been proposed by Craft, Fu, Launder and Tselepidakis [26] and Speziale, Sarkar and Gatski [27]. The former has demonstrated improved predictions of strongly swirling flows and the latter has performed better in homogeneous shear flows with rotation. They are however still at an early stage of testing and validation in a wider range of flows. For example, initial application to homogeneous shear flow with curvature (Tselepidakis, provate communication) did not replicate such improvements.

\section{CONCLUDING REMARKS}

A multigrid procedure for calculating turbulent jets in crossflow has been presented. Multigrid convergence rates are demonstrated for laminar flow. There is some degradation in performance with increase in complexity of the turbulence model, but the convergence rates are still quite impressive in comparison to those for single grids. The two turbulence models predict nearly the same level of agreement of mean streamwise velocity with experimental data. But the RSM predicts Reynolds stresses which are in much better agreement with experiments.

\section{ACKNOWLEDGMENT}

The computations were performed on the Cray YMP computer of the NAS program at NASA Ames Research Center, Moffet Field, California.

\section{REFERENCES}

1. Y. Kamotani, and I. Greber, Experiments on a turbulent jet in crossflow, AIAA J. 10, 14251429 (1972).

2. D. Crabb, D.F.G. Durao, and J.H. Whitelaw, A round jet normal to a crossflow, ASME, $J$ Fluids Engg. 103, 142-153 (1981).

3. K.N. Atkinson, Z.A. Khan, and J.H. Whitelaw, Experimental investigation of opposed jets discarging normally into a cross-stream, J. Fluid Mech. 115, 493-504 (1982).

4. J. Andreopoulos, and W. Rodi, An experimental investigation of jets in a crossflow J. Fluid Mech. 138, 93-127 (1984).

5. J. Andreopoulos, On the structure of jets in a crossflow, J. Fluid Mech. 157, 163-197 (1985).

6. S.A. Sherif, and R.H. Pletcher, Measurements of the flow and turbulence characteristics of round jets in crossflow, ASME, J. Fluids Engg. 111, 165-171 (1989). 
7. S.V. Patankar, D.K. Basu, and S.A. Alpay, Prediction of three dimensional velocity field of a deflected turbulent jet, ASME J. Fluids Engg. 99, 758-762, (1977)

8. W.P. Jones, and J.J. McGuirk, Computations of a round turbulent jet discharging into a confined crossflow, in: Turbulent Shear Flows 2, (Springer 1980) pp. 233-245.

9. A.O. Demuren, Numerical calculations of steady three-dimensional turbulent jets in cross flow, Comp. Meth. App. Mech. Engg. 37, 309-328 (1983).

10. K.C. Karki, and H.C. Mongia, Recent developments in computational combustion dynamics, AIAA Paper No. AIAA-89-2808, (1989).

11. A. O. Demuren, Modeling turbulent jets in crossflow, in: Encyclopedia of Fluid Mechanics, 2, (Gulf Publishing Co. 1985) pp. 430-465.

12. R.W. Claus, and S.P. Vanka, Multigrid calculations of a jet in crossflow, AIAA Paper No. AIAA-90-0444, (1990).

13. B.E. Launder, and D.B. Spalding, The numerical computation of turbulent flows, Comp. Meth. App. Mech. Engg. 3, 269-289 (1974).

14. B.E. Launder, G.J. Reece, and W. Rodi, Progress in the development of a Reynolds stress turbulence closure. J. Fluid Mech. 68, 537-566 (1975).

15. A.O. Demuren and W. Rodi, Calculation of turbulence-driven secondary motion in noncircular ducts, $J . \quad$ Fluid Mech., 140, 189-222, (1984)

16. S.V. Patankar, Numerical Heat Transfer and Fluid Flow, (McGrawHill 1980)

17. A. Jameson and T.J. Baker, Solution of the Euler equations for complex configurations, AIAA paper 83-1929.

18. C.M. Rhie, A pressure based Navier-Stokes Solver using the multigrid method, AIAA paper no. AIAA-86-0207 (1986)

19. C.M. Rhie, and W.L. Chow, Numerical study of the turbulent flow past an airfoil with trailing edge separation, AIAA J., 21, 1525-1532, (1983)

20. M. Peric, A finite volume method for the prediction of three dimensional fluid flow in complex ducts, Ph.D. Thesis, (University of London, London 1985).

21. J.P. van Doormaal, and B.D. Raithby, Enhancements of the SIMPLE method for predicting incompressible fluid flows, Numer. Heat Trans. 7, 147-163 (1984).

22. G.J. Shaw and S. Sivaloganathan, On the smoothing properties of the SIMPLE pressurecorrection algorithm, Int. J. Numer. Meth. in Fluids, 8, 441-461, (1988) 
23. A. Brandt, Multi-level adaptive solutions to boundary-value problems, Math. of Comp. 31, 330-390 (1977).

24. A.O. Demuren, Application of multi-grid methods for solving the Navier-Stokes equations, Proc. Inst. Mech. Engrs. 203, 255-265 (1989).

25. S.P. Vanka, Block-implicit multi-grid solution of Navier-Stokes equations in primitive variables, J. Comput. Phys. 65, 138-158 (1986).

26. T. Craft, S. Fu, B.E. Launder and D.P. Tselepidakis, Developments in Modelling the turbulent second-moment pressure correlations, University of Manchester Institute of Science and Technology, Manchester, UK, Rept. TFD/89/1, (1989)

27. C.G. Speziale, S. Sarkar and T.B. Gatski, Modelling the pressure-strain correlation of turbulence: an invariant dynamical systems approach, J. Fluid Mech., 227, 245-272, (1991) 


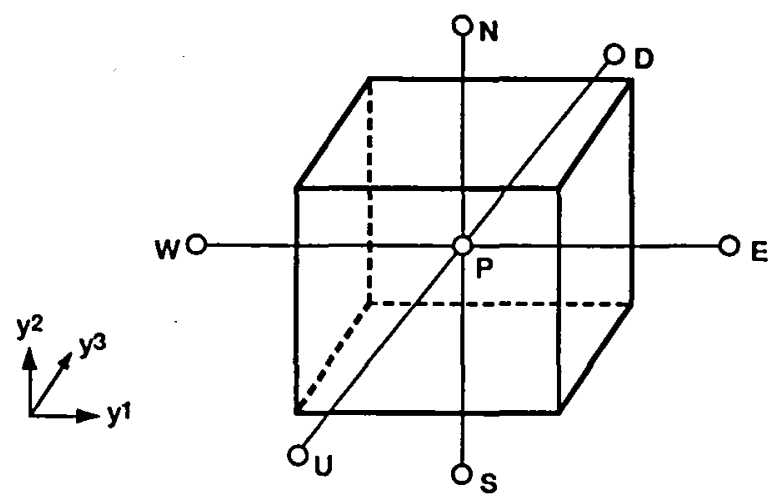

Figure 1.-Control volume showing node $P$ and its nearest neighbors.

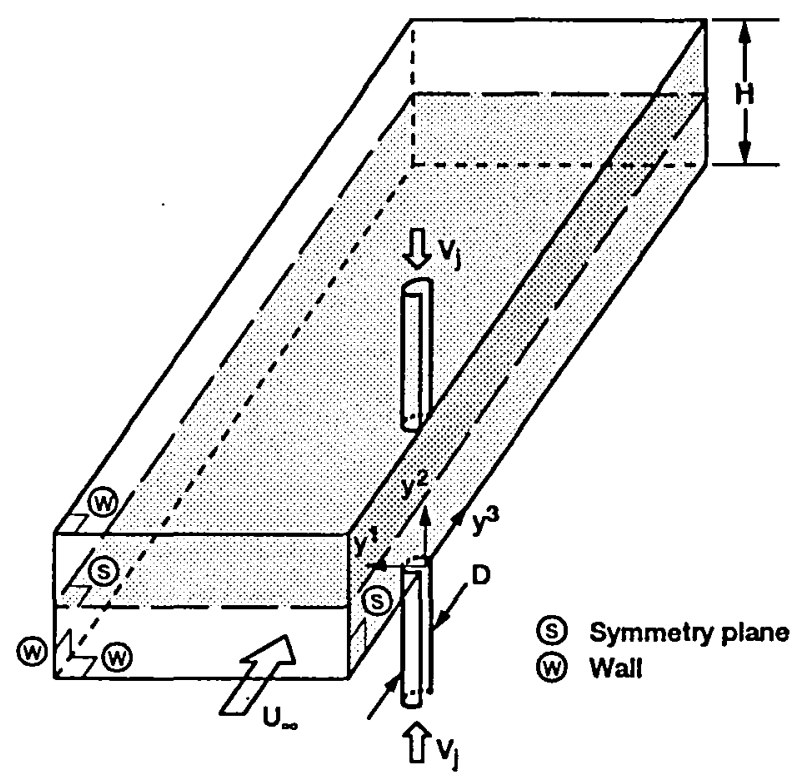

Figure 2.-Pair of opposed jets in crossflow. 


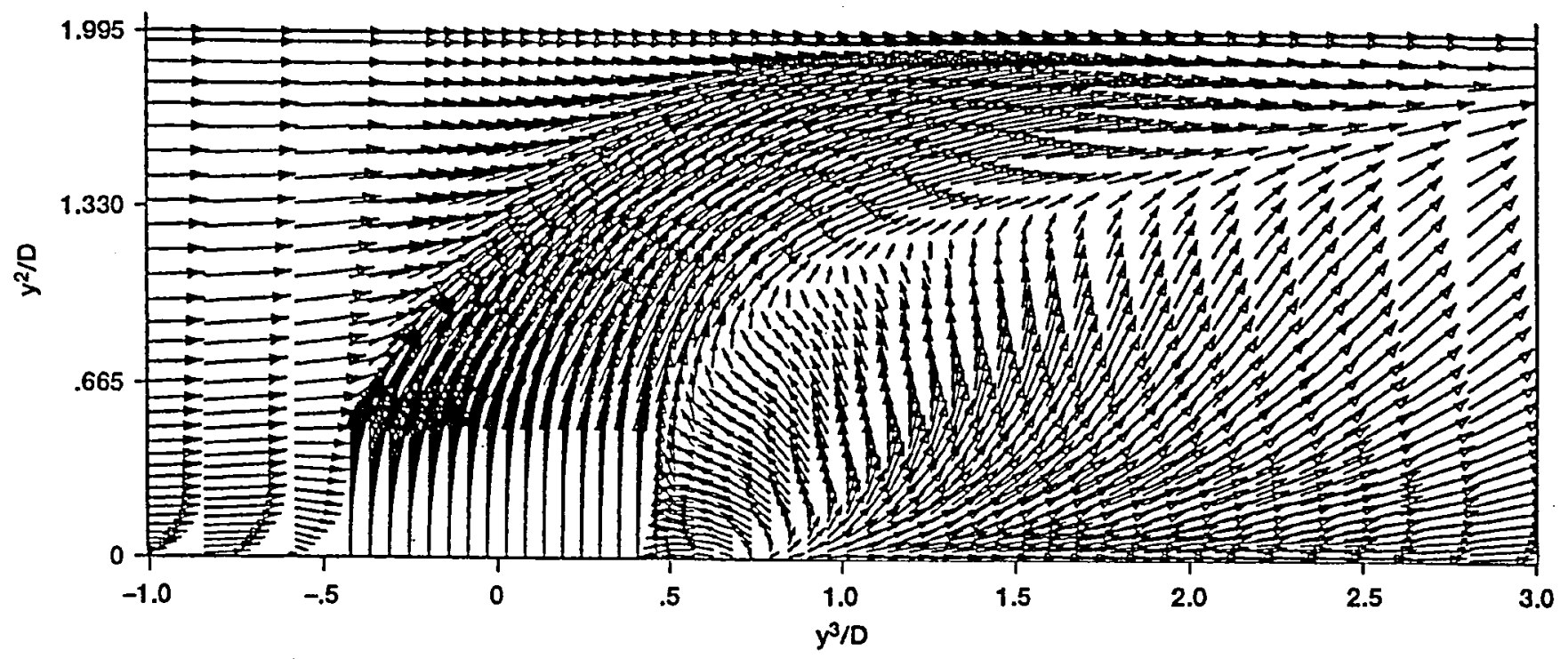

(a) Near field.

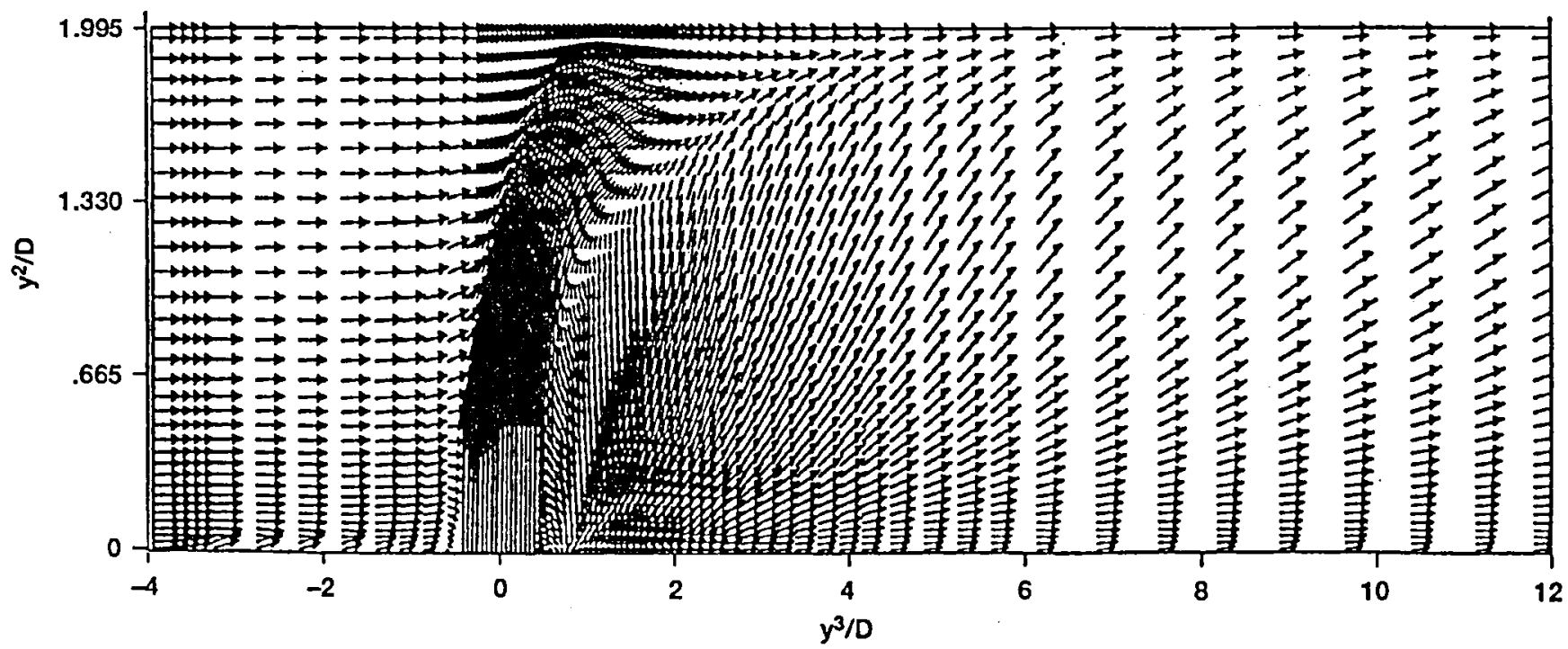

(b) Whole field.

Figure 3.-Computed velocity vectors in center plane, $R e=10^{5}, R=1.8$. 


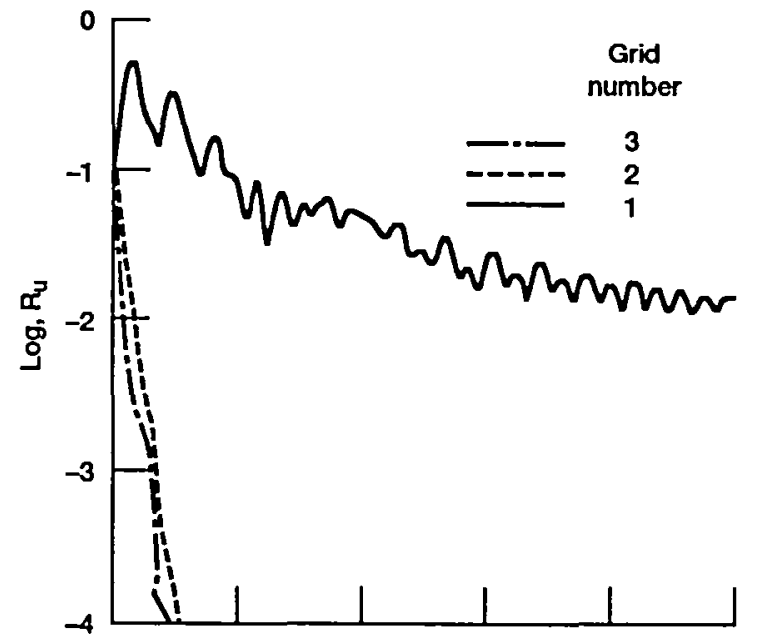

(a) Residual $U_{1}$ mom.

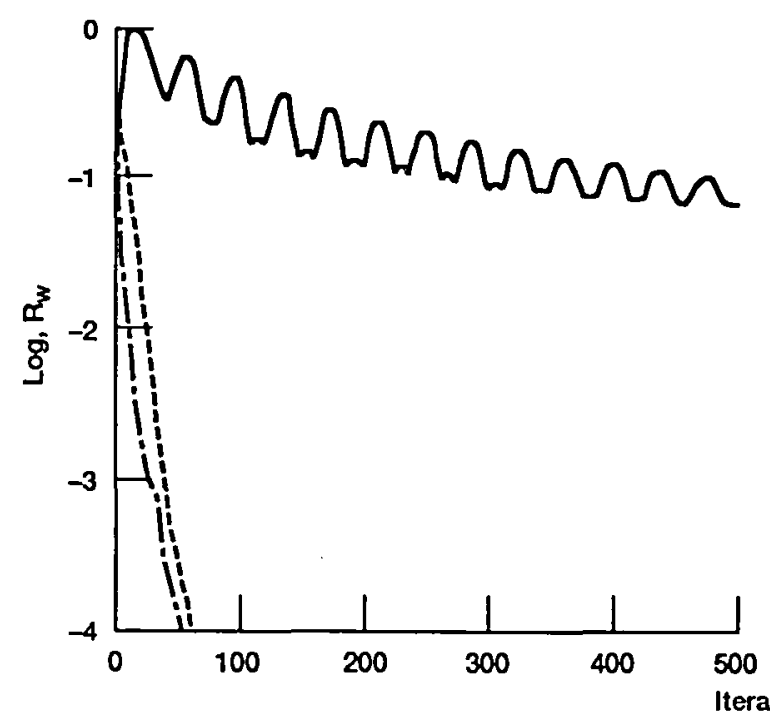

(c) Residual $U_{3}$ mom.

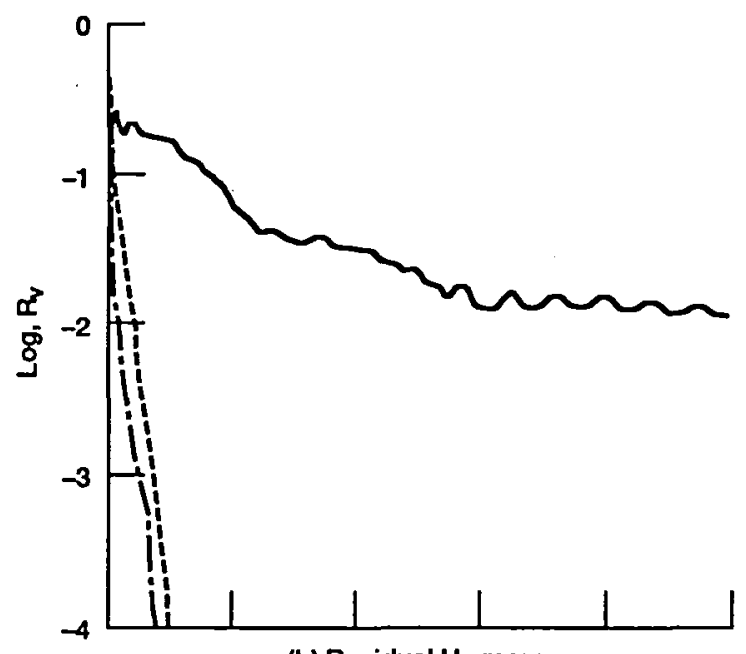

(b) Residual $U_{2}$ mom.

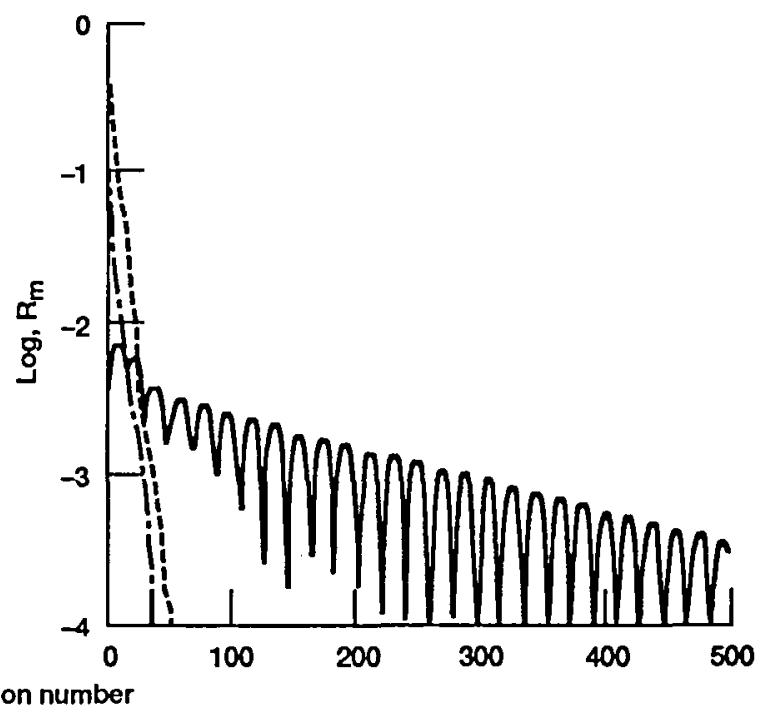

(d) Residual mass.

Figure 4.-Residual history; laminar jet in crossflow, $R e=100, R=1.8$.
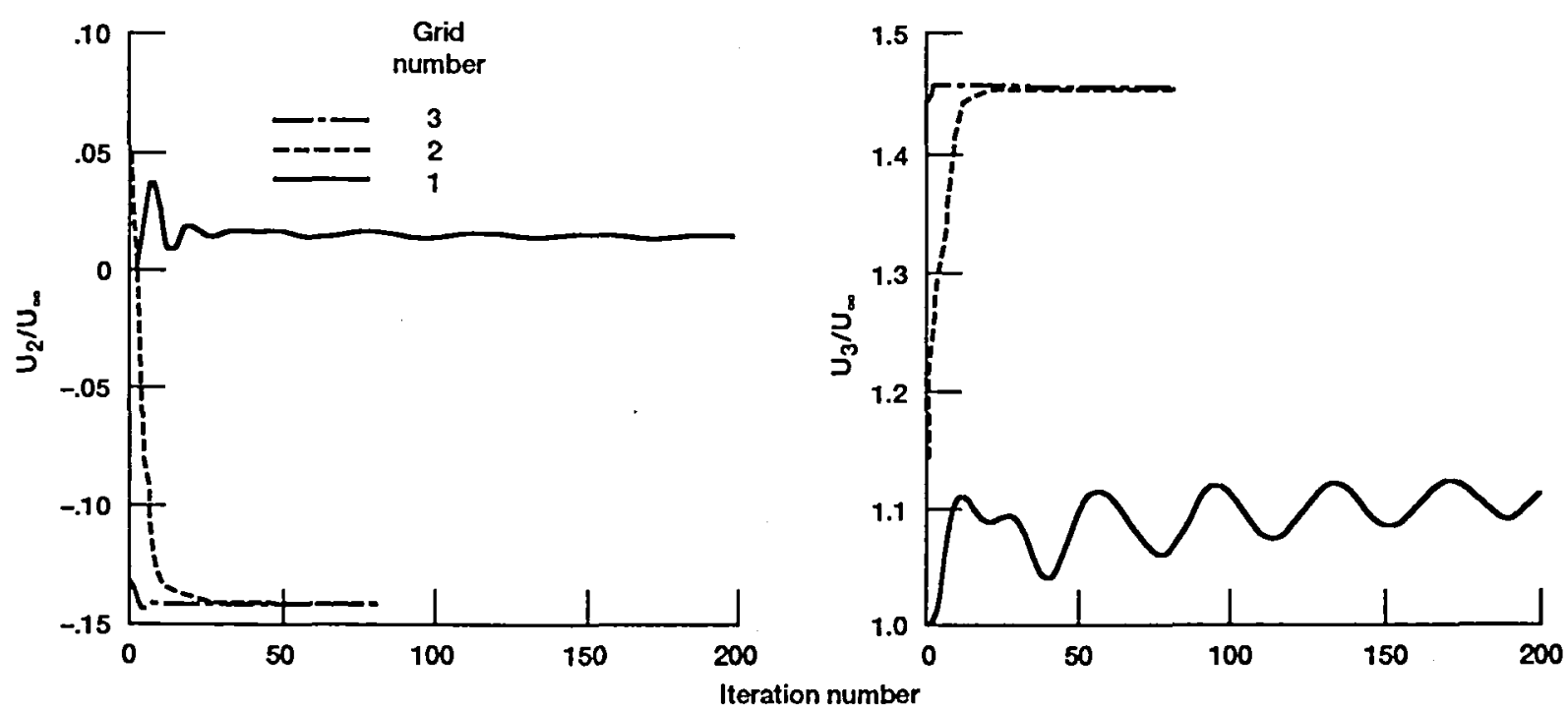

Figure 5.-Velocity history at point (1D, 1D, 1D): same conditions as Fig. 4. 


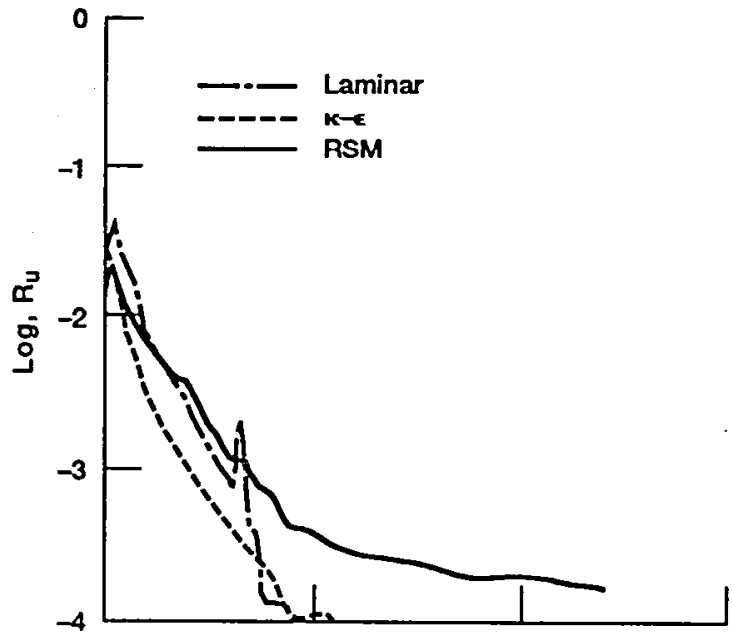

(a) Residual $U_{1}$ mom.

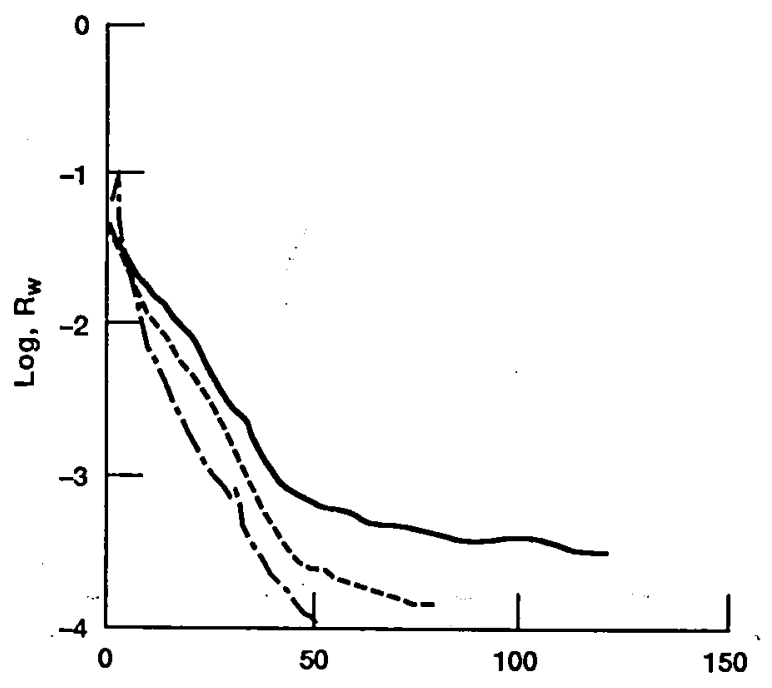

(c) Residual $U_{3}$ mom.

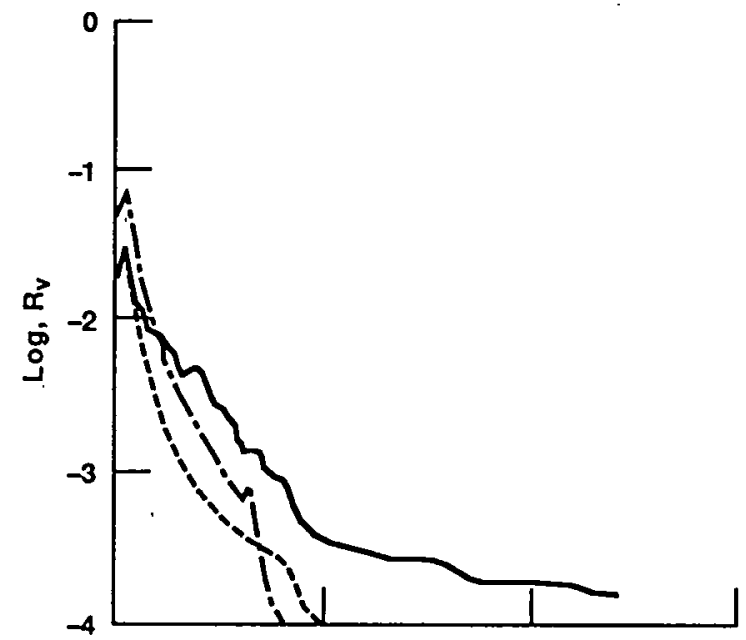

(b) Residual $\mathrm{U}_{2}$ mom.

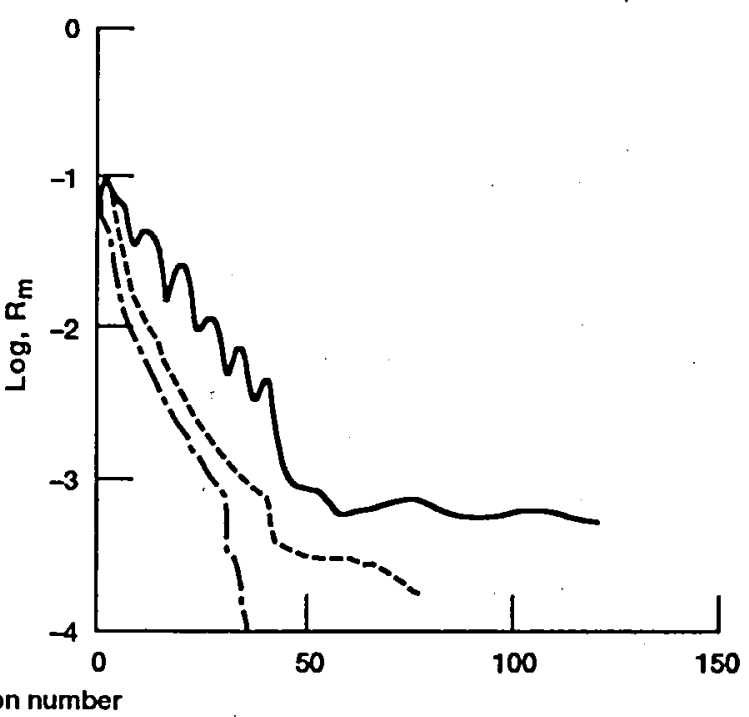

(d) Residual mass.

Figure 6.-Comparison of residual histories: laminar, $\kappa-\epsilon$ model, and RSM computations.
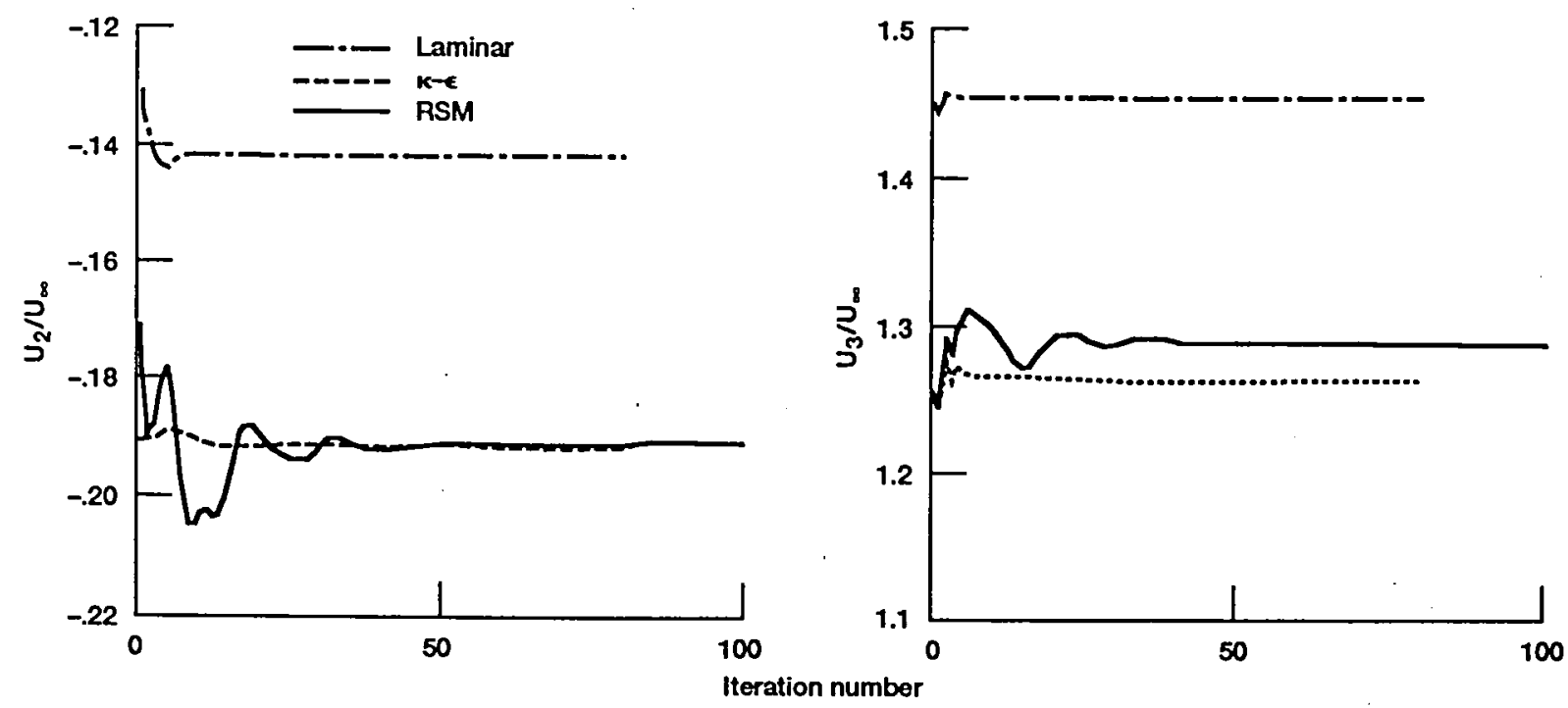

Figure 7.-Velocity histories at point (1D, 1D, 1D): laminar, $k \in$ model, and RSM computations. 


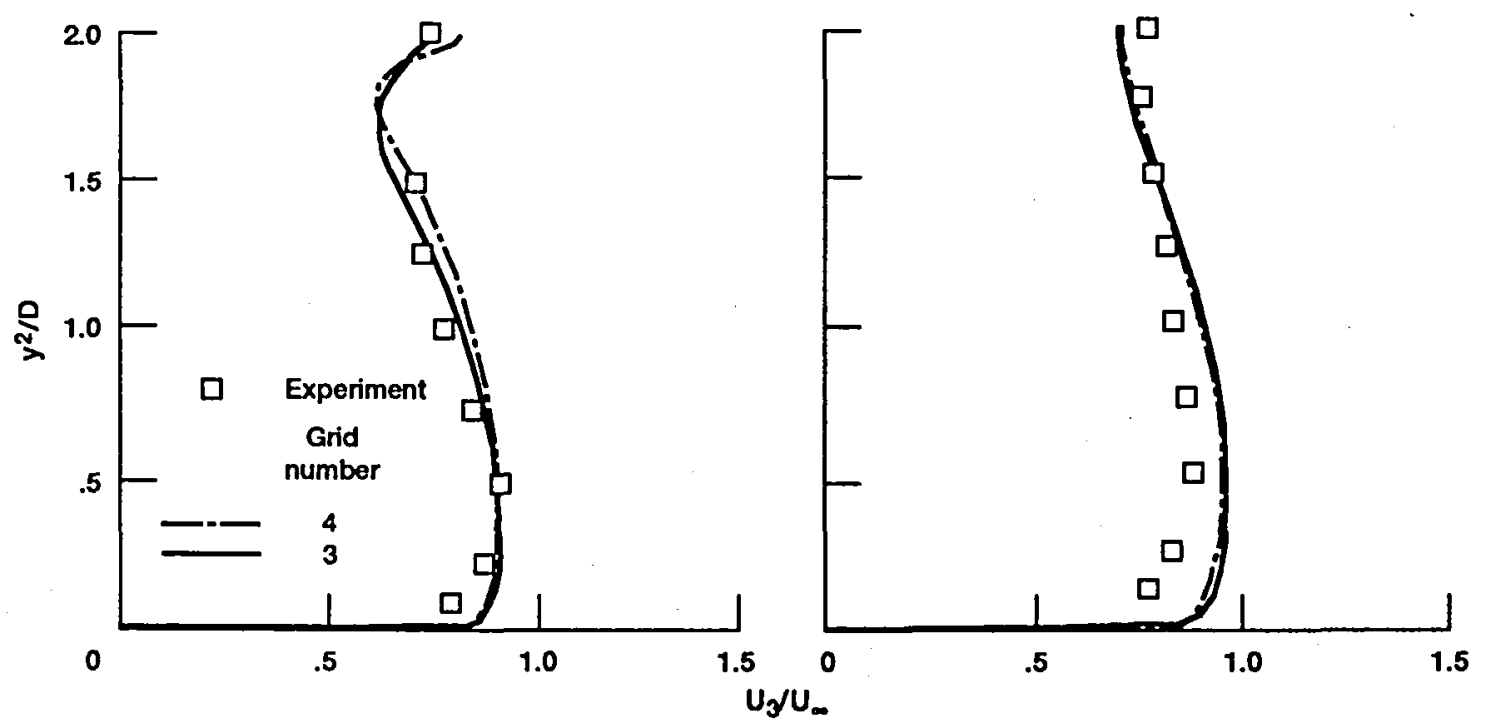

$\begin{array}{ll}\text { (a) } y^{3}=6 D & \text { (b) } y^{3}=8 D \text {. }\end{array}$

Figure 8. - Grid dependency test, $R e=10^{5}, A=1.8$. 


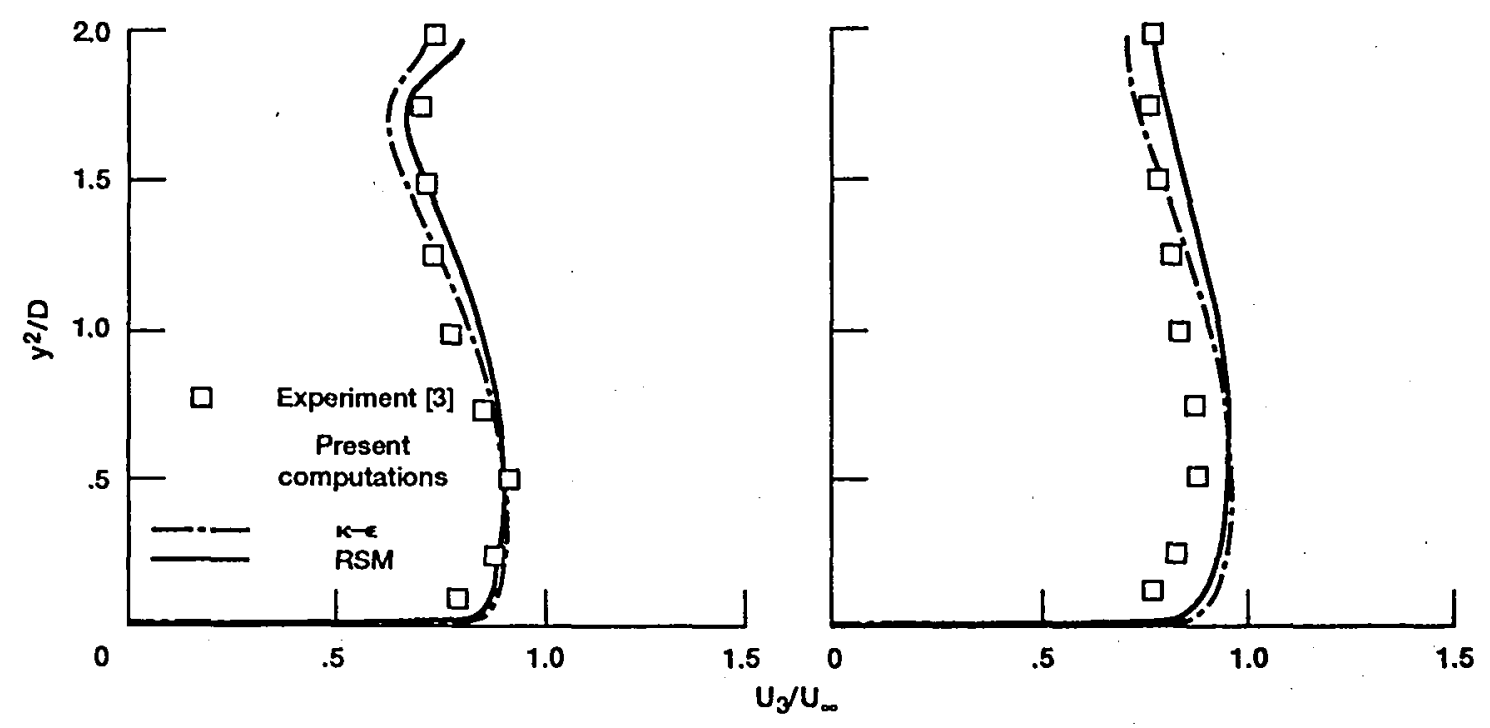

(a) $\mathrm{y}^{3}=6 \mathrm{D}$.

(b) $y^{3}=8 D$.

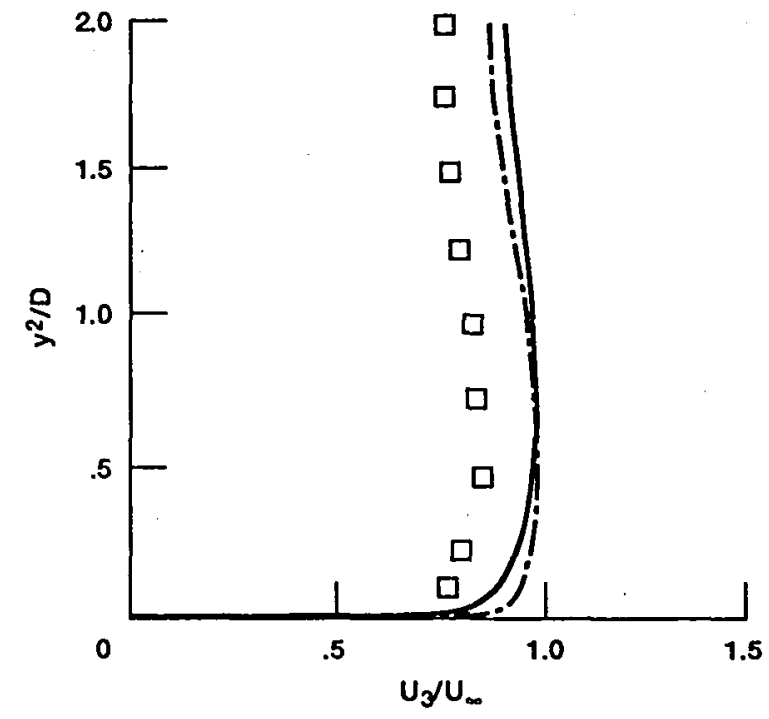

(c) $\mathrm{y}^{3}=120$.

Figure 9.-Comparison of streamwise velocity profiles along $y=0$. 

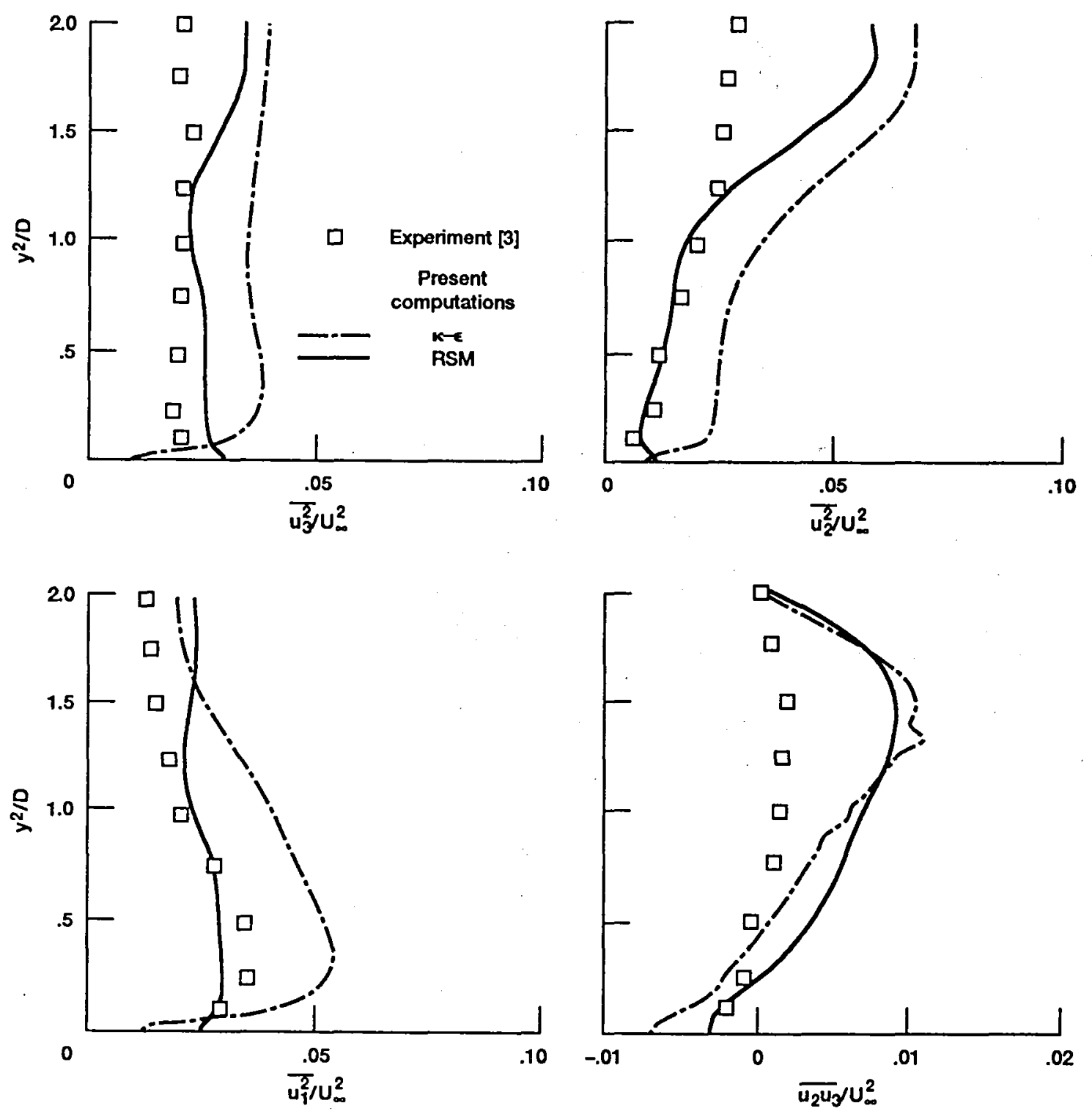

Figure 10.-Comparison of Reynolds stresses along $\left(y^{1}, y^{3}\right)=(0,80)$. 

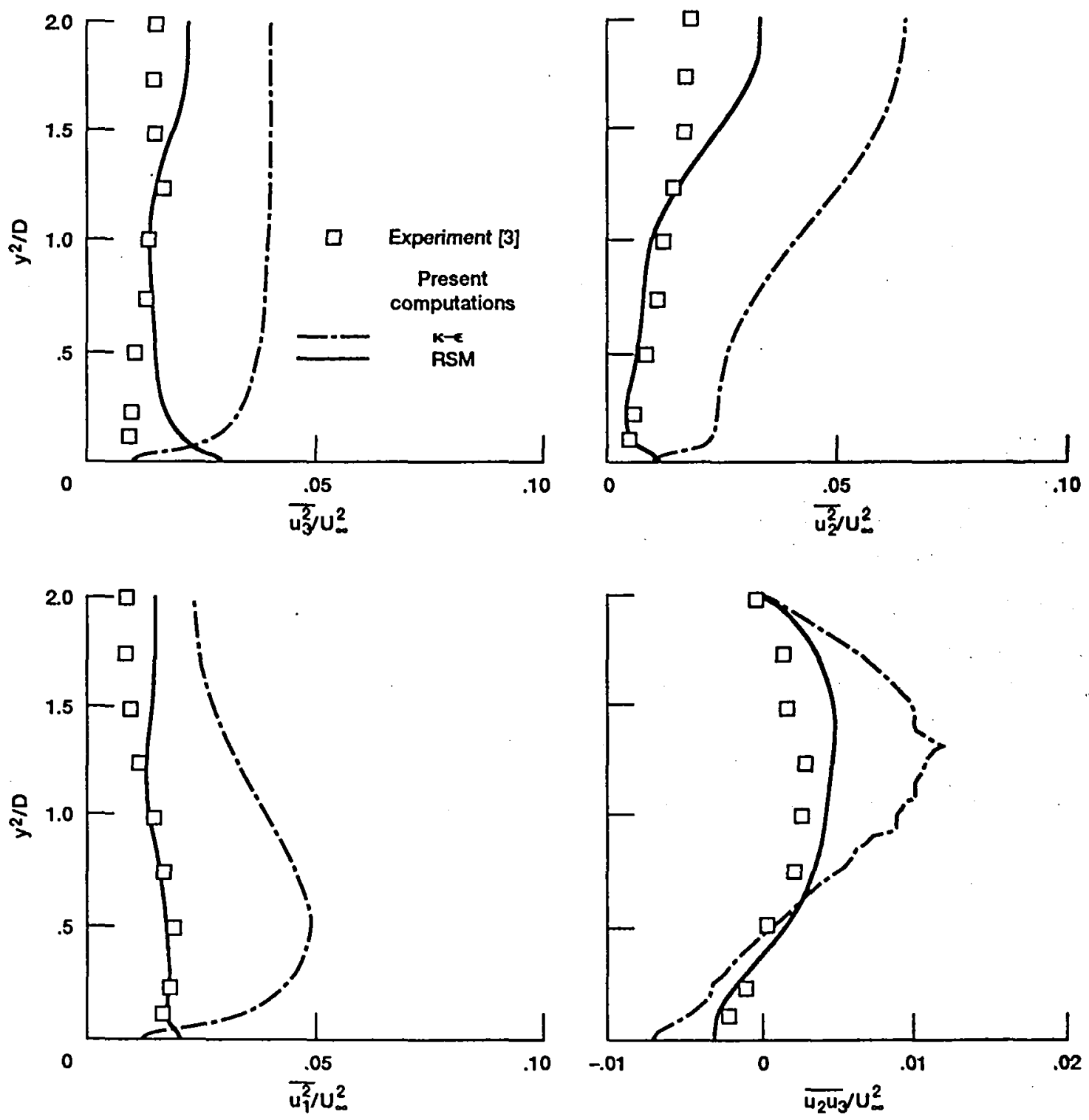

Figure 11.-Comparison of Reynolds stresses along $\left(y^{1}, y^{3}\right)=(0,12 D)$. 
Public reporting burden for this collection of information is estimated to average 1 hour per response, Including the time for reviewing instructlons, searching existing data sources, gathering and malntaining the data needed, and completing and reviewing the collection of Information. Send comments regarding this burden estimate or any other aspect of this collection of information, including suggestions for reducing this burden, to Washington Headquarters Services, Directorate for information Operations and Reports, 1215 Jefferson Davis Highway, Sulte 1204, Arlington, VA 22202-4302, and to the Office of Management and Budget, Paperwork Peduction Project (0704-0188), Washington, DC 20503.
1. AGENCY USE ONLY (Leave blank)
2. REPORT DATE
November 1991
3. REPORT TYPE AND DATES COVERED
Technical Memorandum

4. TITLE AND SUBTITLE

Multigrid Acceleration and Turbulence Models for Computations of 3D Turbulent Jets in Crossflow

6. AUTHOR(S)

A.O. Demuren

\section{PERFoRMING ORGANIZATION NAME(S) AND ADDRESS(ES)}

National Aeronautics and Space Administration

Lewis Research Center

Cleveland, Ohio 44135-3191

5. FUNDING NUMBERS

WU-505-62-21

9. SPONSORING/MONITORING AGENCY NAMES(S) AND ADDRESS(ES)

National Aeronautics and Space Administration

Washington, D.C. 20546-0001

8. PERFORMING ORGANIZATION REPORT NUMBER

E-6658

11. SUPPLEMENTARY NOTES

A.O. Demuren, Old Dominion University, Department of Mechanical Engineering and Mechanics, Norfolk, Virginia 23529 and

Institute for Computational Mechanics in Propulsion and Center for Modeling of Turbulence and Transition, NASA Lewis Research

Center (work funded under Space Act Agreement C-99066-G). ICOMP Program Director: Louis A. Povinelli (216) 433-5818.

12a. DISTRIBUTION/AVAILABILITY STATEMENT

12b. DISTRIBUTION CODE

Unclassified - Unlimited

Subject Category 34

\section{ABSTRACT (Maximum 200 words)}

A multigrid method is presented for the calculation of three-dimensional turbulent jets in crossflow. Turbulence closure is achieved with either the standard $k-\varepsilon$ model or a Reynolds Stress Model (RSM). Multigrid acceleration enables convergence rates which are far superior to that for a single grid method to be obtained with both turbulence models. With the k- $\varepsilon$ model the rate approaches that for laminar flow, but with RSM it is somewhat slower. The increased stiffness of the system of equations in the latter may be responsible. Computed results with both turbulence models are compared with experimental data for a pair of opposed jets in crossflow. Both models yield reasonable agreement with mean flow velocity but RSM yields better prediction of the Reynolds stresses.

\begin{tabular}{|c|c|c|c|}
\hline \multicolumn{3}{|c|}{$\begin{array}{l}\text { 14. SUBJECT TERMS } \\
\text { Jets; Reynolds stress; Turbulence models; Computational fluid dynamics }\end{array}$} & \begin{tabular}{|} 
15. NUMBER OF PAGES \\
22 \\
16. PRICE CODE \\
$\mathrm{AO} 3$ \\
\end{tabular} \\
\hline $\begin{array}{l}\text { 17. SECURITY CLASSIFICATION } \\
\text { OF REPORT } \\
\text { Unclassified }\end{array}$ & $\begin{array}{l}\text { 18. SECURITY CLASSIFICATION } \\
\text { OF THIS PAGE } \\
\text { Unclassified }\end{array}$ & $\begin{array}{l}\text { 19. SECURITY CLASSIFICATION } \\
\text { OF ABSTRACT } \\
\text { Unclassified }\end{array}$ & 20. LIMITATION OF ABSTRACT \\
\hline NSN 7540-01-280-5500 & & & $\begin{array}{l}\text { andard Form } 298 \text { (Rev. 2-89) } \\
\text { scribed by ANSI Std. Z39-18 } \\
\text { 3-102 }\end{array}$ \\
\hline
\end{tabular}


National Aeronautics and Space Administration

Lewis Research Center ICOMP (M.S. 5-3)

Cleveland, Ohio 44135

Offlcial Business

Penalty for Private Use $\$ 300$
FOURTH CLASS MAIL.

\section{ADDRESS CORRECTION REQUESTED}

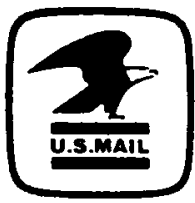

Poslage and Fees Paid National Aeronautics anc Space Adminisiration NASA 451 